\title{
$3^{\text {a }}$ Conferência Municipal de Saúde de Várzea Paulista: a participação da sociedade no processo de priorização e compromisso político'
}

\author{
$3^{\text {rd }}$ Varzea Paulista's Municipal Conference of Health: \\ the participation of society in prioritizing proposals and \\ political commitment
}

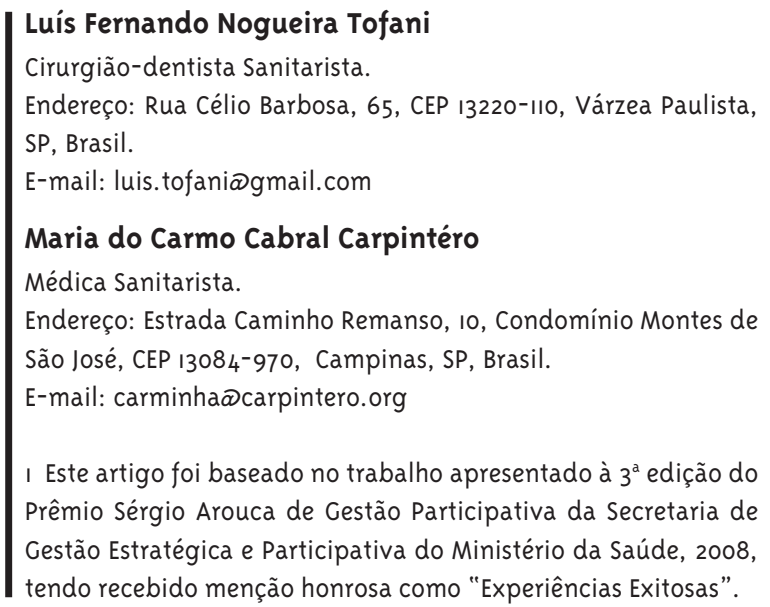

\section{Resumo}

0 artigo apresenta o relato de experiência da $3^{\mathrm{a}}$ Conferência Municipal de Saúde de Várzea Paulista, ocorrida em 2008, cuja organização teve como objetivos envolver a sociedade na análise da situação de saúde do município, de forma a priorizar necessidades em saúde e transformar o relatório final em uma carta de compromisso político. Foram realizadas Plenárias Locais, Pré-Conferências Regionais e a Conferência Municipal, com fluxo ascendente de propostas e delegados, nas quais o tema "Garantindo o Direito à Saúde" foi debatido através de cinco eixos temáticos correspondentes aos blocos do Pacto pela Saúde. Inovou-se com a atividade de priorização, através da limitação do número de propostas de cada região a serem encaminhadas para a Conferência Municipal. O Relatório Final foi encaminhado aos candidatos a prefeito, solicitando-se o compromisso com as deliberações. A realização da Conferência de forma ascendente, com etapas locais e regionais, garantiu a participação da comunidade, a representatividade dos delegados eleitos e das propostas aprovadas. A "priorização coletiva" qualificou o debate garantindo a pactuação com a sociedade de um projeto viável. 0 debate acerca da governabilidade ampliou-se para a intersetorialidade, gerando moções de apelo a outras secretarias municipais. A grande contribuição deste processo para o município foi a oferta de espaços de debate entre os diversos 
olhares, que favoreceu o ensino-aprendizagem e a formação política dos participantes. 0 comprometimento político obtido dos candidatos à sucessão municipal evidenciou o empenho dos atores na transformação da política municipal de saúde em uma política de estado, não de governo.

Palavras-chave: Gestão em Saúde; Saúde Pública; Conferência de Saúde; Controle Social.

\section{Abstract}

The $3^{\text {rd }}$ Health Conference of Varzea Paulista was organized with the objective of involving local society in the analysis of municipal health conditions, so that priorities in health needs could be established and published in a white paper that would be used to gain political commitment of candidates at the forthcoming town hall election. Local meetings and regional pre-conferences were conducted as preparatory activities for the Municipal Conference. In them, representatives and propositions were chosen, in accordance with the theme "Ensuring Health Right", which was developed along the five themes proposed by the Health Pact. The process of defining the priorities was an innovation, through limiting the number of regional proposals sent to Municipal Conference. The white paper was forwarded to candidates for mayor, so that they could commit with the planning established for municipal health authority's actions. The structure of Conference organization, with local and regional stages, made possible the participation of citizens, followed by election of representatives and approval of proposals. Collective prioritizing ensured a social pact that is workable. The debate about governance led to motions for intersectoral activities among municipal departments. One of conference's major contributions was to offer spaces for debate of different opinions, which promoted learning. Politic commitment of candidates for mayor showed a movement in the direction of turning public health a state policy, and not only government action.

Keywords: Health Management; Public Health; Health Conference; Social Control. 


\section{Introdução}

A criação do Sistema Único de Saúde - SUS - no Brasil, no bojo do movimento pela redemocratização do país na década de 8o, deu-se a partir do engajamento dos movimentos populares de saúde e da organização de trabalhadores do setor saúde com sanitaristas da academia e políticos progressistas, naquilo que ficou conhecido como Movimento da Reforma Sanitária. A participação da comunidade no SUS, instituída pela Constituição “cidadã" de 1988 (Brasil, 1988) em seu artigo 198 e reafirmada no artigo $7^{\circ}$ da Lei Orgânica da Saúde, 8.o8o de 1990 (Brasil, 1990a), foi regulamentada pela Lei 8.142 do mesmo ano (Brasil, 199ob), sendo exercida através das Conferências e Conselhos de Saúde.

No decorrer dos 20 anos de implantação do SUS, a participação da sociedade na análise da situação de saúde, na definição de prioridades e na formulação de políticas públicas e seu acompanhamento representa uma verdadeira reforma no estado de direito no Brasil, ampliando as relações entre a democracia representativa e a direta, garantindo o fortalecimento de um sistema de saúde público universal que promova a qualidade de vida e a saúde integral de forma equitativa à população. O SUS é uma proposta contra-hegemônica frente à reforma gerencial do estado brasileiro iniciada na década de 9o, a partir das definições do Consenso de Washington de uma política neoliberal (Pereira, 2008); esta preconiza a terceirização das áreas de apoio, a privatização dos setores produtivos estatais e a publicização das áreas sociais como políticas focais, destinadas aos excluídos das possibilidades do mercado; o SUS tem resistido apesar das dificuldades no financiamento, na gestão e na modelagem assistencial, garantindo a saúde como direito de todos e dever do estado, principalmente através da institucionalização do controle social.

Por princípio ético-político-ideológico, a gestão municipal de Várzea Paulista eleita para o quadriênio 2005-2008 tomou a participação popular como diretriz de governo ${ }^{2}$, tendo atuado nestes anos de forma a ampliar os espaços de formação política e de participação da sociedade através da realização de 13 Conferências Municipais dos mais variados temas, a implantação de 11 Conselhos Municipais e a instituição do Orçamento Participativo na cidade. Na Secretaria de Saúde foram implantados 16 Conselhos Locais em unidades e serviços, o Conselho Municipal foi reorganizado em sua estrutura e base legal, foram realizadas 2 Conferências Municipais de Saúde e 2 cursos para conselheiros, além da implantação da Ouvidoria do SUS e do Programa de Voluntariado.

É este o cenário no qual descrevemos e analisamos a experiência da realização da $3^{\text {a }}$ Conferência Municipal de Várzea Paulista em 2008. Seus objetivos, expressos pelo Conselho Municipal de Saúde de Várzea Paulista ${ }^{3}$, foram o de envolver grande parte da sociedade local, incluindo gestores, trabalhadores e usuários de saúde, para de forma ascendente analisar a situação de saúde do município; priorizar coletivamente as necessidades em saúde como subsídio à elaboração do Plano Municipal de Saúde para o próximo quadriênio; eleger membros para o Conselho Municipal de Saúde com representatividade social e familiaridade com as propostas aprovadas para qualificar o exercício das funções de conselheiro; transformar o Relatório Final em uma carta de compromisso político de todos os candidatos à sucessão municipal.

Ela teve ampla participação social e, realizada de forma ascendente, introduziu a priorização coletiva como parte do processo. 0 debate abordou a intersetorialidade na saúde, o comprometimento político com as deliberações da conferência e a organização de seus eixos de acordo com o Pacto pela Saúde.

\section{Apresentação da Experiência}

No ano de 2007 foi realizada a $13^{\text {a }}$ Conferência Nacional de Saúde, precedida de conferências estaduais, regionais e municipais; mais de 4 .ooo delegados, representando trabalhadores, usuários e gestores do SUS do Brasil inteiro, dela participaram. 0 relatório final foi composto por mais de 600 propostas aprovadas a partir do debate realizado em todas as

2 Proposta para o SUS de Várzea Paulista. Várzea Paulista, SP: Secretaria Municipal de Saúde, 2005. Mimeo.

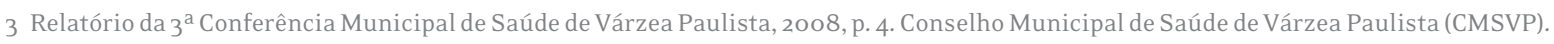
Mimeo. 
partes do país (Brasil, 2007). Várzea Paulista havia realizado sua $2^{\text {a }}$ Conferência Municipal de Saúde em 2005, para a elaboração do Plano Municipal de Saúde 2006-2009, mas fez a opção de realizar uma etapa municipal da $13^{\text {a }}$ Conferência Nacional de Saúde. 0 debate prioritário foi centrado nos 03 grandes eixos do SUS; foram elaboradas propostas de abrangência estadual e nacional, encaminhadas às etapas posteriores, além da eleição de delegados. O Conselho Municipal de Saúde decidiu então, após amplo debate, pela realização da $3^{\text {a }}$ Conferência Municipal de Saúde no início de 2008, focada mais em questões locais.

Uma comissão paritária (Conasems, 2003) formada ad hoc elaborou uma proposta de regimento interno que previa a realização de duas etapas anteriores à conferência municipal, as plenárias locais e as pré-conferências regionais, com fluxo ascendente de propostas e delegados. A realização de uma conferência municipal em etapas não era algo inédito se verificarmos as experiências de outros municípios, mas no caso de Várzea Paulista, imersa num processo de participação social intenso em todas as áreas, foi uma proposta nova e muito bem recebida.

0 tema da Conferência - Garantindo o Direito à Saúde - foi debatido através de 5 eixos temáticos: Gestão em Saúde e Participação Social; Atenção Básica em Saúde; Assistência Especializada e Hospitalar; Assistência Farmacêutica e Vigilância em Saúde. Estes eixos correspondem aos cinco blocos de financiamento do Pacto pela Saúde, o que facilitaria a transformação posterior das propostas em ações do Plano Municipal de Saúde, que também seria organizado em blocos para compatibilização com o Plano Plurianual (PPA).

Dentro da metodologia proposta e aprovada no Regimento, destacou-se a atividade de "priorização das propostas" nas Pré-Conferências Regionais. Tratava-se de um exercício de ampliação da participação direta da sociedade no processo de escolha de suas necessidades frente ao cenário possível, através da limitação do número de propostas por eixo a serem encaminhadas da região para a $3^{\text {a }}$ Conferência Municipal, a partir do condensado das plenárias locais. Para que esta atividade não "engessasse" o processo, ou que permitisse que propostas realmente importantes fossem excluídas do Rela- tório Final, havia certa flexibilidade, uma margem de segurança de 2 ou 3 propostas a mais ou a menos que poderiam ser encaminhadas por eixo, além do exercício de composição de propostas semelhantes ou complementares.

Como inovação, foi instituída em paralelo à conferência a I Mostra de Experiências do SUS Várzea Paulista, nas quais os serviços públicos municipais de saúde poderiam apresentar, através de exposição de pôsteres, experiências realizadas nas áreas de assistência à saúde, gestão em saúde ou saúde coletiva, compartilhando o trabalho de suas equipes com todos os delegados da conferência. Uma comissão paritária de membros do Conselho Municipal de Saúde, após julgamento, premiaria as três melhores experiências com um recurso financeiro que deveria ser empregado na própria unidade, mediante plano de trabalho aprovado pelo respectivo Conselho Local de Saúde.

Com o iminente final do mandato dos membros do Conselho Municipal de Saúde, propôs-se que a eleição (CNS, 2003) para renovação fosse realizada ao final da Conferência, elegendo conselheiros entre os delegados; este processo garantiria a representatividade no Conselho e o compromisso com as deliberações da $3^{\text {a }}$ Conferência Municipal de Saúde. Esta estratégia também visava instituir um Conselho Municipal de Saúde conhecedor das propostas aprovadas na conferência, possibilitando assim um melhor acompanhamento do futuro Plano Municipal de Saúde.

Foi também aprovado no regimento de Saúde que

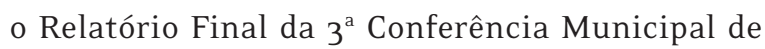
Saúde deveria ser encaminhado a todos os futuros candidatos a prefeito nas eleições de outubro, para conhecimento e compromisso dos planos de governo com suas deliberações. Isso garantiria que a definição da política pública de saúde para o próximo quadriênio respeitasse as diretrizes assistenciais e de participação da comunidade no Sistema Único de Saúde aprovadas pelo pleno da Conferência.

A dinâmica da Conferência, além de ter sido discutida amplamente com diversos setores da sociedade, buscou incorporar dispositivos que ampliassem a mobilização social e o envolvimento com a sua realização, assim como com a efetivação das propostas e demais encaminhamentos dela oriundos. A 
descrição das realizações em termos de participação nas diferentes atividades e em termos do conteúdo das deliberações aprovadas permite uma análise da abrangência dos objetivos que envolveram a realização da Conferência, como se verá a seguir.

\section{Discussão}

O processo promoveu um amplo debate em 18 plenárias locais, realizadas em cada serviço de saúde, com o envolvimento de mais de 300 participantes, incluindo usuários, trabalhadores, prestadores e gestores da rede municipal de Várzea Paulista. Estas foram seguidas por 3 pré-conferências regionais, que reuniam paritariamente representantes destas categorias.

Para a primeira pré-conferência regional, da região norte da cidade, foram escolhidos 56 delegados e 72 propostas levantadas nas cinco Unidades Básicas. Após debate em grupos organizados por eixos temáticos, alterações de texto com inclusões, exclusões, fusões de propostas e priorização, foram aprovadas 36 propostas e 31 delegados para a Conferência Municipal.

Na pré-conferência da região oeste, foram encaminhados 52 delegados debateram e selecionaram 63 propostas elaboradas nas quatro Unidades Básicas da região, no CAPS, na Farmácia Popular e na sede da Secretaria de Saúde. Após o trabalho nos grupos, a plenária aprovou 42 propostas e 48 delegados para a etapa municipal.

Um total de 59 delegados e 58 propostas levantadas nas 3 Unidades Básicas da região Centro-Leste, além do Hospital da Cidade, Ambulatório de Especialidades e CEO, foram encaminhados para a pré-conferência desta região. Foram aprovadas 41 propostas e eleitos 47 delegados para a Conferência.

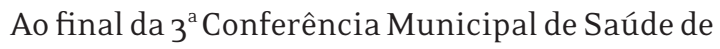
Várzea Paulista foram aprovadas 100 propostas que têm bastante propriedade enquanto representação das necessidades de saúde do município. A seguir, listamos as propostas por eixo de ação.

\section{Eixo Gestão em Saúde e Participação Popular:}

- elaboração um site específico da saúde para a disseminação de informações e conhecimentos úteis,
- utilização dos meios de comunicação divulgando as conferências de saúde e outras notícias de interesse público,

- fixação nas UBS de cartazes em locais visíveis informando à população a composição do quadro de conselheiros e datas de reuniões,

- implantação de sistema integrado de informática entre os equipamentos de saúde,

- garantia de curso básico de informática aos servidores, melhora e ampliação da educação em saúde com o apoio de outras secretarias,

- ampliação do acervo didático da Secretaria de Saúde,

- busca de novas parcerias com universidades e escolas técnicas para investir na Educação Permanente dos servidores e ampliação de campos de estágio;

- ampliação de recursos financeiros municipais, estaduais e federais para a saúde,

- ampliação e readequação do quadro de funcionários, reorganização das estratégias de cadastramento do Cartão SUS,

- incentivo à participação dos conselheiros locais de saúde nas reuniões do Conselho Municipal de Saúde,

- criação de grupos e cartilhas específicas para doenças mais prevalentes,

- manutenção da política de educação permanente, - disponibilização nos serviços de quadro padronizado com horário de funcionamento, nome do gerente e horário dos profissionais de saúde e criação de murais específicos para trabalhadores e para usuários,

- renovação periódica da frota de veículos e garantia de agilidade na manutenção, garantia de consultas de retorno em especialidades oferecidas fora do município, agilidade para manutenção predial,

- reforço às atribuições dos Conselhos Locais, melhoraria na segurança nos equipamentos de saúde do município,

- implantação de fóruns entre serviços de uma mesma região para discussão de problemas em comum, 
- garantia do quadro de médicos necessários para a demanda do município,

- fortalecimento do programa de voluntariado, garantia prioritária de transporte para pacientes referenciados pela rede SUS,

- proposta ao Colegiado de Gestão Regional de Saúde a realização de plenárias regionais de conselheiros, e

- garantia do uso de crachás de identificação por todos os servidores

\section{Eixo Atenção Básica em Saúde:}

- implantação de horário noturno de atendimento nas UBS de grande demanda,

- humanização das relações entre profissionais de saúde e usuários,

- ampliação das UBS incluindo consultório odontológico,

- salas de reuniões e espaços cobertos para Lian Gong e outras práticas integrativas,

- qualificação da recepção das Unidades ampliando

o quadro de pessoal, melhorar na ambiência das UBS,

- garantia do atendimento da assistência social na saúde,

- implantação dos Programas de Saúde do Adolescente e do Idoso,

- implantação de Agentes Comunitários de Saúde em todas as UBS,

- garantia do atendimento de casos agudos na rede básica independente de agendamento, construção uma nova unidade na região Oeste,

- construção de um prédio próprio para UBS instalada em prédio alugado,

- reorganização do cronograma de férias dos profissionais médicos,

- garantia do matriciamento em Saúde Mental para a rede,

- garantia de atendimento de clínico geral diariamente nos dois períodos de atendimento em todas UBS's,

- implantação de Saúde da Família em outras regiões da cidade,
- garantia do matriciamento dos especialistas para a rede,

- valorização das práticas complementares,

- realização de cursos de capacitações para Cuidadores Informais,

- implantação efetiva da territorialização,

- continuidade dos programas de combate ao alcoolismo e violência,

- fluxo para coletas de exames em sincronia com retorno clínico, e

- especializado e pré-operatório.

Eixo Atenção Especializada e Hospitalar:

- implantação de cozinha própria no Hospital da Cidade,

- aquisição de novos equipamentos para oftalmologia,

- adoção de novos protocolos clínicos e de encaminhamento,

- implantação de ouvidoria no Hospital, implantação de maternidade municipal com centro cirúrgico,

- aumento e modernização da frota de ambulâncias,

- implantação de plantão odontológico no Hospital,

- informação à população sobre o Acolhimento com Classificação de Risco,

- contratação da equipe médica dificultando a ausência de plantonistas no Hospital,

- ampliação do atendimento em endodontia,

- oferta de próteses odontológicas, ampliação do número de consultas em especialidades com demanda reprimida,

- reestruturação do CAPS para funcionamento 24 horas,

- implantação de Residência Terapêutica, implantação de CAPS álcool e drogas,

- oferta de laqueadura e vasectomia no planejamento familiar,

- reorganização e monitoramento do sistema de cotas de consultas e exames, e

- mutirões de cirurgias e exames com demanda reprimida, criação de prontuário único em meio eletrônico acessível a todos os serviços de saúde. 


\section{Eixo Assistência Farmacêutica:}

- viabilização de local para recebimento,

- estocagem e distribuição de suprimentos,

- implantação de dispensário de medicamentos no Hospital,

- implantação de novos medicamentos na padronização com aprovação da Comissão de Farmácia e Terapêutica,

- contratação de auxiliares de farmácia,

- garantia de fornecimento ininterrupto de medicação de uso contínuo,

- reforço à prescrição de medicamentos da Relação Municipal de Medicamentos Essenciais, estruturação da assistência farmacêutica dentro do organograma,

- estruturação dos dispensários das UBS com supervisão,

- construção de uma central de suprimentos,

- transporte adequado para viabilizar o atendimento logístico de suprimentos e

- prioridade no fornecimento dos medicamentos aos pacientes SUS.

\section{Eixo Saúde Coletiva:}

- ampliação do acesso à castração de cães e gatos e implantação do o programa de "posse responsável", - manutenção do plano de enfrentamento intersetorial ao Aedes Aegypti (dengue),

- realização de educação em saúde coletiva para a população e de coleta específica para pilhas, baterias, resíduos de raios-X e outros resíduos perigosos,

- ampliação dos programas de controle de pragas urbanas e vetores,

- ampliação dos espaços de denúncia para a população, acolhendo denúncias de risco à saúde nas UBS, e

- implantação de ações à saúde do trabalhador e projeto intersetorial de educação ambiental, além da construção de Centro de Controle de Zoonoses.

Como se percebe, em todos os eixos houve uma tendência de propostas com grande especificidade local e, ao mesmo tempo, com grande capacidade de diálogo com os eixos e os princípios e diretrizes do SUS. Não apenas a identificação de problemas e de ações para enfrentá-los em cada localidade, mas também a proposição de iniciativas capazes de fortalecer as capacidades locais.

Muito mais que os aspectos quantitativos de participação de delegados e propostas, bastante positivos, foi importante a qualidade do processo enquanto debate técnico e político e o envolvimento da comunidade. Foram verdadeiros espaços de troca entre os diversos olhares, incluindo as possibilidades técnicas pelas equipes profissionais, as possibilidades político-legais-financeiras pelos gestores e as demandas trazidas pela sociedade. A participação de membros do Conselho Municipal de Saúde e dos Conselhos Locais de Saúde, além dos agentes do Orçamento Participativo, fizeram toda a diferença. A partir de diversas formações realizadas ao longo de 3 anos e do efetivo exercício da participação social, estes cidadãos promoveram um debate que propiciou um verdadeiro processo de ensino-aprendizagem para todos os segmentos envolvidos. A organização dos eixos de debate pelos cinco blocos do Pacto pela Saúde propiciou a todos uma melhor compreensão das diferentes dimensões e da complexidade do sistema de saúde.

Como ponto chave do processo, a diretriz regimental de limitar o número de propostas de cada região que seriam encaminhadas para o pleno da

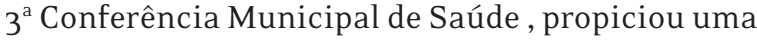
experiência inédita de "priorização coletiva". Os próprios grupos definiram critérios de prioridade para escolha de propostas, debatendo o que era realmente "importante para a região", o que era realmente "novo" e não continuidade de ações que já estavam ocorrendo, o que não poderia ser resolvido "de imediato" e que demandaria investimento financeiro e previsão orçamentária com solução entre médio e longo prazo, o que era da governabilidade da Secretaria Municipal de Saúde ou dependeria de outras esferas (de gestão do SUS ou de outros setores da administração pública). Este trabalho de priorização normalmente é feito a partir de um imenso relatório que contém propostas, na maioria das vezes redundantes, ambíguas e contraditórias, de forma isolada pelo gestor municipal, com participação de no máximo sua equipe de gestão.

Sobre a governabilidade, o debate ampliou-se bastante, discutindo se "os determinantes sociais" do processo saúde-doença que não são de competên- 
cia exclusiva do setor saúde deveriam ou não constar do relatório final. A maioria destas propostas foi organizada em moções, a partir da organização, sistematização, coleta de assinaturas, defesa e aprovação dos delegados, em sua maioria usuários. 0 resultado disso foram 15 moções encaminhadas a órgãos como as Secretarias Municipais de Gestão Pública, de Assistência Social, de Infra-estrutura, de Segurança Pública, de Meio Ambiente e de Educação, além da APAE, SABESP, Colegiado de Gestão Regional e Secretaria de Estado da Saúde, sobre temas como saneamento, manutenção, carreira dos servidores, áreas de lazer, financiamento da saúde, manutenção predial, coleta seletiva de lixo, transporte, moradores de rua, segurança pública e participação popular.

Ao final da Conferência, os mais de 100 participantes da plenária final, além de aprovar as propostas debatidas, elegeram os 20 membros titulares e os 20 membros suplentes do Conselho Municipal de Saúde, que assumiram o compromisso de acompanhar o próximo plano municipal de saúde que seria organizado a partir do Relatório Final. Ainda propuseram que este relatório fosse encaminhado a todos os candidatos a prefeito nas eleições de outubro, o que foi feito, cobrando-se o compromisso político de que, quem quer que fosse eleito respeitaria as deliberações para elaboração de seu Plano de Governo, garantindo sustentabilidade da política municipal de saúde pactuada com a sociedade. Um Conselho Municipal assim estabelecido, com informação e conhecimento significativos dos encaminhamentos aprovados pela conferência municipal para acompanhar a implementação do plano durante a gestão do próximo governo tem condições melhores de efetuar o controle social, num salto qualitativo importante para que o plano de governo não represente apenas as iniciativas da base de apoio do candidato eleito.

\section{Conclusões}

A partir do vivenciado, podemos afirmar a título de conclusões que o processo de ampliação das instâncias de participação social em Várzea Paulista, em especial na saúde, representou um verdadeiro processo de reforma do estado, garantindo a articulação entre a democracia direta e a representativa e transformando a gestão pública municipal em promotora da cidadania através dos Conselhos e Conferências.

A realização da $3^{\text {a }}$ Conferência Municipal de Saúde de Várzea Paulista, de forma ascendente, com etapas prévias locais e regionais, garantiu a ampliação do acesso à participação da comunidade, assim como da representatividade dos delegados eleitos e das propostas aprovadas. Também é destaque a grande mobilização que produziu no território do município.

A metodologia de realização da Conferência teve capacidade de fortalecer a participação no desenho de propostas com alto potencial de diálogo com a realidade de cada local. 0 processo de "priorização coletiva" qualificou o debate, garantindo a pactuação com a sociedade de um projeto viável, a partir de um Relatório Final “enxuto" organizado pelos cinco blocos de financiamento do Pacto pela Saúde, facilitando sua conversão no futuro Plano Municipal de Saúde, assim como no Plano Plurianual (PPA) e propostas orçamentárias (LDO e LOA).

O debate acerca da governabilidade sobre as propostas ampliou-se para a intersetorialidade e os determinantes sociais do processo saúde-doença, desencadeando a organização de moções de apelo a vários setores do estado e da sociedade a partir de questões significativas para a população.

A eleição dos membros do Conselho Municipal de Saúde entre os delegados presentes na Conferência foi um marco de compromisso e ampliação da capacidade de exercício das atribuições dos conselheiros na formulação e acompanhamento da saúde no município.

A grande riqueza do processo foi a oferta de espaços de debate entre os diversos olhares, que propiciou um processo educativo de ensinoaprendizagem e formação política dos gestores, prestadores, trabalhadores e usuários participantes. Também os dispositivos de participação social na saúde apresentaram-se fortemente como espaços de aprendizagem e de ensino no sistema de saúde, demonstrando que não apenas a atenção ou, mais freqüentemente, a assistência, pode ensinar aos trabalhadores da área da saúde.

O comprometimento político dos eventuais candidatos à sucessão municipal com as propostas 


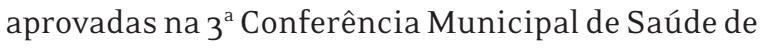
Várzea Paulista demonstram um grande empenho dos atores envolvidos na transformação da política municipal de saúde e do SUS em uma política de estado e não de governo, garantindo-se a participação da comunidade como eixo estruturante.

Espera-se que seja possível acompanhar e avaliar o quanto este processo terá capacidade de influenciar o cotidiano da gestão, da educação, da atenção e da participação na saúde de Várzea Paulista no próximo período, em um desdobramento desta análise sobre o processo de realização da $3^{\text {a }}$ Conferência Municipal.

\section{Referências}

BRASIL. Constituição (1988). Constituição da

República Federativa do Brasil. Brasília, DF:

Senado, 1988.

BRASIL. Lei n. ${ }^{\circ}$ 8.o8o, de 19 de Setembro de 1990. Dispõe sobre as condições para a promoção, proteção e recuperação da saúde, a organização e o funcionamento dos serviços correspondentes e dá outras providências. Diário Oficial da União, Brasília, DF, 20 set. 1990 a.
BRASIL. Lei n. ${ }^{0}$ 8.142, de 28 de setembro de 1990. Dispõe sobre a participação da comunidade na gestão do Sistema Único de Saúde (SUS) e sobre as transferências intergovernamentais de recursos financeiros na área da saúde e dá outras providências. Diário Oficial da União, Brasília, DF, 31 dez. $1990 b$.

BRASIL. Ministério da Saúde. Conselho Nacional de Saúde. Saúde e qualidade de vida. Políticas de Estado e desenvolvimento: relatório final. Conferência Nacional de Saúde, 13., Brasília, DF, 2007 (Série C. Projetos, Programas e Relatórios).

CONSELHO NACIONAL DE SAÚDE - CNS.

Resolução n. ${ }^{\circ}$ 333, de 4 de novembro de 2003.

Define Diretrizes para criação, reformulação estruturação e funcionamento dos Conselhos de Saúde. Brasília, DF: CNS, 2003.

CONSELHO NACIONAL DOS SECRETÁRIOS MUNICIPAIS DE SAÚDE - CONASEMS. Conferências Municipais de Saúde passo a passo. Brasília, DF: Conasems, 2003.

PEREIRA, E. T. Educação política: uma experiência com o orçamento participativo. Campinas: Alínea e Átomo, 2008. 